\title{
Connection Damage Detection of Double Beam System under Moving Load with Genetic Algorithm
}

\author{
Hougui ZHANG*, Ruixiang SONG**, Jie YANG***, Dan WU****, Yingjie WANG***** \\ *Beijing Municipal Institute of Labour Protection, Beijing, 100054, China, E-mail: zhanghougui@bmilp.com \\ **Beijing Municipal Institute of Labour Protection, Beijing, 100054, China, E-mail: rxsonj@ 163.com \\ ***Beijing Municipal Institute of Labour Protection, Beijing, 100054, China, E-mail: junting325@163.com \\ ****Beijing Municipal Institute of Labour Protection, Beijing, 100054, China, E-mail: popwudan@163.com \\ ******School of Civil Engineering, Beijing Jiaotong University, Beijing 100044, China, E-mail: ceyjwang@bjtu.edu.cn \\ crossref http://dx.doi.org/10.5755/j02.mech.25500
}

\section{Introduction}

Double beam system is a kind of important beams in civil, and mechanical engineering etc. $[1,2]$. Usually the double beam system can be divided into the upper beam and lower beam, where the parallel beams are connected continuously by a viscoelastic layer or discretely by a series of supporting units. Taking the railway slab track as an example, the rail can be regarded as the upper beam and the slab as the lower beam [3, 4]. For the embankment structures, the pavement structure can be treated as an upper beam, and the geo-cell reinforced layer idealized as the lower beam [5]. Therefore, the dynamic behaviors of these infrastructures travelled by moving vehicles is the concern of most researchers.

The vibration problem of double beam system excited by moving loads is good developed and explored during the past decades. For the double beam system vibration, Abu-Hilal studied the dynamic response of a double beam system under a moving constant load, and the dynamic displacements of both beams are given in analytical closed forms [6]. Zhang et al obtained the dynamic responses of an elastically connected simply supported double-beam system under compressive axial load and arbitrarily distributed continuous loads, where the upper beam and lower beam are continuously joined by a Winkler elastic layer [7]. Balkaya et al investigated the free vibration of a double beam system with both end simply supported and fixed, and the motion of the system is solved by the Differential Transform Method (DTM)[8]. Huang and Liu obtained the free vibration characteristics and the forced vibration responses of the double beam system through the free interface substructure method, and pointed out that the mode localization phenomena would occur in such a weakly coupled system [9]. Koziol adopted wavelet approximation method combined with Adomian's decomposition to study the dynamic response of a double-beam resting on a nonlinear viscoelastic foundation and subjected to a series of moving loads [10]. Jiang et al. presented an analytical expression of dynamic response of a double beam system under successive moving loads and the results are verified through general FEM software ANSYS [11]. A comprehensive investigation on the literatures indicates that most of the existing studies are focused on the dynamic behaviors of double beam system under free vibration and moving loads, and there is no paper investigated the damage detection of the connection between the upper and lower beams for the double beam system.
This paper is organized as follows. In Section 2 the dynamic model of double beam system under moving load is presented and followed the integration procedure solution. In Section 3 the dynamic accelerations of the double beam system with and without connection damage are compared and the feasibility of connection damage detection using structural responses is verified. In Section 4 the process of connection damage detection of double beam system using the structural dynamic responses combined with genetic algorithm is proposed. In Section 5 some certain connection damage cases between the upper and lower beams, including simple damage and multiple damages, are studied through the numerical investigation. Last, the paper is concluded in Section 6.

\section{Mathematical formulation}

In this paper, the dynamic responses of a double beam system under moving load are studied, as shown in Fig 1. To simplify the mathematical formulation of the double beam system vibration under moving load, some assumptions are list as follows:

1. The double beam system is composed of two beams, which are represented as upper beam and lower beam, and both beams are modeled as simple supported elastic Bernoulli-Euler beam.

2. The upper beam and lower beam are connected by a series of linear springs with stiffness $k$, and the interval between two adjacent springs is $l$.

3. In this study, the moving load is simplified as a moving sinusoidal force $P(t)=P_{0} \sin \left(\omega_{0} t\right)$ with the constant frequency $\omega_{0}$ and the amplitude $P_{0}[12]$.

4. The connection damage of the double beam system can be regarded as some mechanical properties reduction such as stiffness reduction, and the stiffness of the damaged spring is $k_{r}$.

5. At the initial time $t=0$, the moving sinusoidal load is located at the left end of the beam and travels to the right end at a constant speed $v$.

As shown in Fig. 1, the force acting on the double beam system is simplified as a moving sinusoidal force, therefore the dynamic double beam system model is called as moving load model also.

\subsection{Upper beam}

The upper beam is regarded as an elastic Bernoulli-Euler beam with span length $L$, and supported by the 
lower beam via a series of linear springs discretely, as shown in Fig. 1. For the connection damage condition, it is assumed that the stiffness of the $j$ th $(j=1 \sim N)$ spring is reduced as $k_{r}$. The equation of motion for the upper beam with connection damage subjected to moving sinusoidal load can be written as $[13,14]$ :

$$
E_{1} I_{1} \frac{\partial^{4} Z_{1}(x, t)}{\partial x^{4}}+m_{1} \frac{\partial^{2} Z_{1}(x, t)}{\partial t^{2}}+c_{1} \frac{\partial Z_{1}(x, t)}{\partial t}=F_{1}(x, t)
$$

where: $Z_{1}(x, t)$ is the upper beam deflection; $(x, t)$ are the spatial co-ordinate and the time; $m_{1}$ is the constant mass per unit length; $E_{1}$ is the elastic modulus; $I_{1}$ the moment of inertia; $c_{1}$ the damping of the upper beam. $F_{1}(x, t)$ is the force acting on the upper beam, including the moving load and the force from the lower beam, which can be given as:

$$
\begin{aligned}
& F_{1}(x, t)=P_{0} \sin \left(\omega_{0} t\right) \delta\left(x-x_{p}\right)- \\
& -\sum_{j=1}^{d-1} k\left[Z_{1}\left(x_{j}, t\right)-Z_{2}\left(x_{j}, t\right)\right] \delta\left(x-x_{j}\right)- \\
& -\sum_{j=d} k_{r}\left[Z_{1}\left(x_{j}, t\right)-Z_{2}\left(x_{j}, t\right)\right] \delta\left(x-x_{j}\right)- \\
& -\sum_{j=d+1}^{N} k\left[Z_{1}\left(x_{j}, t\right)-Z_{2}\left(x_{j}, t\right)\right] \delta\left(x-x_{j}\right),
\end{aligned}
$$

where: $Z_{2}\left(x_{j}, t\right)$ is the lower beam deflection; $\left(x_{j}, t\right)$ are the spatial co-ordinate of the $j^{\text {th }}$ spring and the time; $x_{p}$ the distance of the moving sinusoidal load from the left-hand of the beam; $\delta(\cdot)$ is the Dirac delta function.

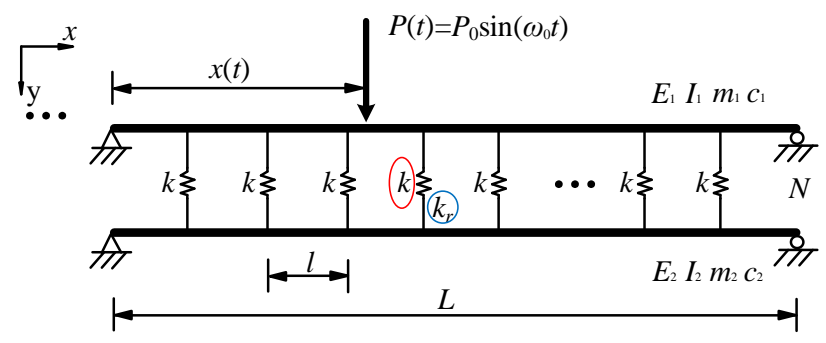

Fig. 1 Double beam system with connection damage under moving sinusoidal load

\subsection{Lower beam}

The lower beam is modelled as an elastic Bernoulli-Euler beam with the same span length as the upper beam, and the equation of motion for the lower beam with connection damage loads can be written as $[15,16]$ :

$$
E_{2} I_{2} \frac{\partial^{4} Z_{2}(x, t)}{\partial x^{4}}+m_{2} \frac{\partial^{2} Z_{2}(x, t)}{\partial t^{2}}+c_{2} \frac{\partial Z_{2}(x, t)}{\partial t}=F_{2}(x, t),
$$

where: $Z_{2}(x, t)$ is the lower beam deflection; $(x, t)$ are the spatial co-ordinate and the time; $m_{2}$ is the constant mass per unit length; $E_{2}$ is the elastic modulus; $I_{2}$ the moment of inertia; $c_{2}$ the damping of the lower beam. $F_{2}(x, t)$ is the force acting on the lower beam, which can be given as:

$$
\begin{aligned}
& F_{2}(x, t)=\sum_{j=1}^{d-1} k\left[Z_{1}\left(x_{j}, t\right)-Z_{2}\left(x_{j}, t\right)\right] \delta\left(x-x_{j}\right)+ \\
& +\sum_{j=d} k_{r}\left[Z_{1}\left(x_{j}, t\right)-Z_{2}\left(x_{j}, t\right)\right] \delta\left(x-x_{j}\right)+ \\
& +\sum_{j=d+1}^{N} k\left[Z_{1}\left(x_{j}, t\right)-Z_{2}\left(x_{j}, t\right)\right] \delta\left(x-x_{j}\right) .
\end{aligned}
$$

\subsection{Solution}

The upper and lower beams are regarded as simple supported beam, respectively, and the $i^{\text {th }}$ mode shape $\phi_{i}(x)$ and circular frequency $\omega_{i}$ of the beam can be written as [17]:

$$
\begin{aligned}
& \phi_{i}(x)=\sin \left(\frac{i \pi}{L} x\right),(i=1,2 \cdots \infty), \\
& \omega_{i}=\left(\frac{i \pi}{L}\right)^{2} \sqrt{\frac{E I}{m}},(i=1,2 \cdots \infty) .
\end{aligned}
$$

With mode superposition method, the displacements of the upper and lower beams can be obtained in terms of modal shapes and corresponding modal displacements as:

$$
\begin{aligned}
& Z_{1}(x, t)=\sum_{i=1}^{\infty} q_{1 i}(t) \phi_{1 i}(x) \quad(i=1,2 \cdots \infty), \\
& Z_{2}(x, t)=\sum_{i=1}^{\infty} q_{2 i}(t) \phi_{2 i}(x) \quad(i=1,2 \cdots \infty),
\end{aligned}
$$

where: $q_{1 n}(t)$ and $q_{2 n}(t)$ are the generalized coordinate associated with the $i^{\text {th }}$ natural mode of the upper and lower beams; $\phi_{1 i}(x)$ and $\phi_{2 i}(x)$ are the $i^{\text {th }}$ mode shape function of both beams.

Substituting Eqs. (7) and (2) into Eq. (1), the equation of motion for the $n$th mode in terms of the generalized displacement $q_{1 n}(t)$ of the upper beam can be given as:

$$
\ddot{q}_{1 n}(t)+2 \xi_{1 n} \omega_{1 n} \dot{q}_{1 n}(t)+\omega_{1 n}^{2} q_{1 n}(t)=\frac{F_{1 n}(t)}{M_{1 n}},
$$

where: $\omega_{1 n}, \xi_{1 n}$, and $M_{1 n}$ are the modal frequency, the damping ratio, and the modal mass of the $n$th mode, respectively, and the generalized force $F_{1 n}(t)$ acting on the upper beam from the moving sinusoidal load and the lower beam is expressed as:

$$
\begin{aligned}
& F_{1 n}(t)=P_{0} \sin \left(\omega_{0} t\right) \phi_{1 n}\left(x_{p}\right)-\sum_{j=1}^{d-1} \sum_{i=1}^{\infty} k q_{1 i}(t) \phi_{1 i}\left(x_{j}\right) \phi_{1 n}\left(x_{j}\right)+\sum_{j=1}^{d-1} \sum_{i=1}^{\infty} k q_{2 i}(t) \phi_{2 i}\left(x_{j}\right) \phi_{1 n}\left(x_{j}\right)- \\
& -\sum_{j=d} \sum_{i=1}^{\infty} k_{r} q_{1 i}(t) \phi_{1 i}\left(x_{j}\right) \phi_{1 n}\left(x_{j}\right)+\sum_{j=d} \sum_{i=1}^{\infty} k_{r} q_{2 i}(t) \phi_{2 i}\left(x_{j}\right) \phi_{1 n}\left(x_{j}\right)-\sum_{j=d+1}^{N} \sum_{i=1}^{\infty} k q_{1 i}(t) \phi_{1 i}\left(x_{j}\right) \phi_{1 n}\left(x_{j}\right)+. \\
& +\sum_{j=d+1}^{N} \sum_{i=1}^{\infty} k q_{2 i}(t) \phi_{2 i}\left(x_{j}\right) \phi_{1 n}\left(x_{j}\right) .
\end{aligned}
$$


Similarly, the equation of motion for the $n$th mode in terms of the generalized displacement $q_{2 n}(t)$ of the lower beam can be given as:

$$
\begin{aligned}
\ddot{q}_{2 n}(t) & +2 \xi_{2 n} \omega_{2 n} \dot{q}_{2 n}(t)+\omega_{2 n}^{2} q_{2 n}(t)=\frac{F_{2 n}(t)}{M_{2 n}}, \quad \text { (11) } \\
& F_{2 n}(t)=\sum_{j=1}^{d-1} \sum_{i=1}^{\infty} k q_{1 i}(t) \phi_{1 i}\left(x_{j}\right) \phi_{2 n}\left(x_{j}\right)-\sum_{j=1}^{d-1} \sum_{i=1}^{\infty} k q_{2 i}(t) \phi_{2 i}\left(x_{j}\right) \phi_{2 n}\left(x_{j}\right)+\sum_{j=d}^{\infty} \sum_{i=1}^{\infty} k_{r} q_{1 i}(t) \phi_{1 i}\left(x_{j}\right) \phi_{2 n}\left(x_{j}\right)- \\
& -\sum_{j=d} \sum_{i=1}^{\infty} k_{r} q_{2 i}(t) \phi_{2 i}\left(x_{j}\right) \phi_{2 n}\left(x_{j}\right)+\sum_{j=d+1}^{N} \sum_{i=1}^{\infty} k q_{1 i}(t) \phi_{1 i}\left(x_{j}\right) \phi_{2 n}\left(x_{j}\right)-\sum_{j=d+1}^{N} \sum_{i=1}^{\infty} k q_{2 i}(t) \phi_{2 i}\left(x_{j}\right) \phi_{2 n}\left(x_{j}\right)
\end{aligned} .
$$

Subsequently, substituting Eqs. (10) and (12) into Eqs. (9) and (11), respectively, and moving the unknown terms with $\left(q_{1 n}, q_{2 n}\right)$ to the left side of the differential equation, where: $\omega_{2 n}, \xi_{2 n}$, and $M_{2 n}$ are the modal frequency, the damping ratio, and the modal mass of the $n$th mode, respectively, and the generalized force $F_{2 n}(t)$ acting on the lower beam from the upper beam is expressed as:

$$
\begin{aligned}
& \ddot{q}_{1 n}(t)+2 \xi_{1 n} \omega_{1 n} \dot{q}_{1 n}(t)+\omega_{1 n}^{2} q_{1 n}(t)+\frac{k}{M_{1 n}} \sum_{j=1}^{d-1} \sum_{i=1}^{\infty} q_{1 i}(t) \phi_{1 i}\left(x_{j}\right) \phi_{1 n}\left(x_{j}\right)+\frac{k_{r}}{M_{1 n}} \sum_{j=d} \sum_{i=1}^{\infty} q_{1 i}(t) \phi_{1 i}\left(x_{j}\right) \phi_{1 n}\left(x_{j}\right)+ \\
& +\frac{k}{M_{1 n}} \sum_{j=d+1}^{N} \sum_{i=1}^{\infty} q_{1 i}(t) \phi_{1 i}\left(x_{j}\right) \phi_{1 n}\left(x_{j}\right)-\frac{k}{M_{1 n}} \sum_{j=1}^{d-1} \sum_{i=1}^{\infty} q_{2 i}(t) \phi_{2 i}\left(x_{j}\right) \phi_{1 n}\left(x_{j}\right)- \\
& \quad-\frac{k_{r}}{M_{1 n}} \sum_{j=d}^{\infty} \sum_{i=1}^{\infty} q_{2 i}(t) \phi_{2 i}\left(x_{j}\right) \phi_{1 n}\left(x_{j}\right)-\frac{k}{M_{1 n}} \sum_{j=d+1}^{N} \sum_{i=1}^{\infty} q_{2 i}(t) \phi_{2 i}\left(x_{j}\right) \phi_{1 n}\left(x_{j}\right)= \\
& =\frac{P_{0} \sin \left(\omega_{0} t\right)}{M_{1 n}} \phi_{1 n}\left(x_{p}\right) . \\
& \ddot{q}_{2 n}(t)+2 \xi_{2 n} \omega_{2 n} \dot{q}_{2 n}(t)+\omega_{2 n}^{2} q_{2 n}(t)+\frac{k}{M_{2 n}} \sum_{j=1}^{d-1} \sum_{i=1}^{\infty} q_{2 i}(t) \phi_{2 i}\left(x_{j}\right) \phi_{2 n}\left(x_{j}\right)+\frac{k_{r}}{M_{2 n}} \sum_{j=d} \sum_{i=1}^{\infty} q_{2 i}(t) \phi_{2 i}\left(x_{j}\right) \phi_{2 n}\left(x_{j}\right)+ \\
& +\frac{k}{M_{2 n}} \sum_{j=d+1}^{N} \sum_{i=1}^{\infty} q_{2 i}(t) \phi_{2 i}\left(x_{j}\right) \phi_{2 n}\left(x_{j}\right)-\frac{k}{M_{2 n}} \sum_{j=1}^{d-1} \sum_{i=1}^{\infty} q_{1 i}(t) \phi_{1 i}\left(x_{j}\right) \phi_{2 n}\left(x_{j}\right)-\frac{k_{r}}{M_{2 n}} \sum_{j=d}^{\infty} \sum_{i=1}^{\infty} q_{1 i}(t) \phi_{1 i}\left(x_{j}\right) \phi_{2 n}\left(x_{j}\right)-. \\
& -\frac{k}{M_{2 n}} \sum_{j=d+1}^{N} \sum_{i=1}^{\infty} q_{1 i}(t) \phi_{1 i}\left(x_{j}\right) \phi_{2 n}\left(x_{j}\right)=0 .
\end{aligned}
$$

It is indicated from Eqs. (13) and (14) that the upper and lower beams are coupled through the springs between them. By combining Eqs. (13) and (14) together, the equations of motion of double beam system subjected moving load in modal space can be given in a matrix form as:

$$
[M]\{\ddot{U}\}+[C]\{\dot{U}\}+[K]\{U\}=\{F\},
$$

where: $[M],[C],[K]$ are the mass, damping and stiffness matrices of double beam system; $(\{U\},\{\dot{U}\},\{\ddot{U}\})$ are the vectors of displacement, velocity, and acceleration, respectively; and $\{F\}$ represents the vector of exciting forces applying to the dynamic system.

Assume $N_{b}$ modes of the upper and lower beams in Eqs (7) and (8) are used in this paper, $\{U\}$ and $\{F\}$ can be given as:

$$
\{U\}=\left[\begin{array}{llllllll}
q_{11} & q_{12} & \cdots & q_{1 N_{b}} & q_{21} & q_{22} & \cdots & q_{2 N_{b}}
\end{array}\right],
$$

$$
\{F\}=p_{f}\left[\begin{array}{llllllll}
\Phi_{11} & \Phi_{12} & \cdots & \Phi_{1 N_{b}} & 0 & 0 & \cdots & 0
\end{array}\right],
$$

where: $P_{f}=\frac{P_{0} \sin \left(\omega_{0} t\right)}{M_{1 n}}, \Phi_{1 i}=\phi_{1 i}\left(x_{p}\right)$.

The mass, damping and stiffness matrices $[M],[C]$, $[K]$ of the double beam system under moving load can be given as:

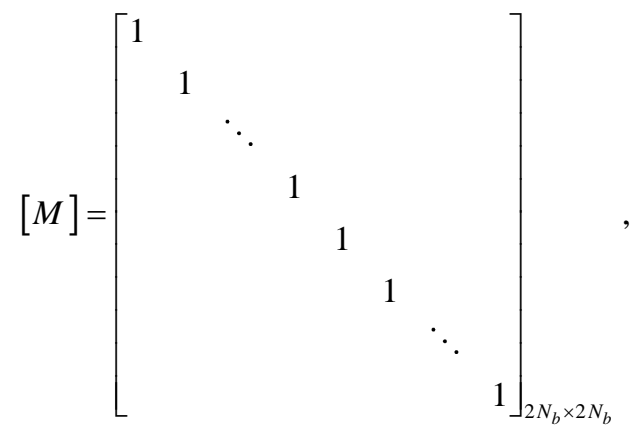




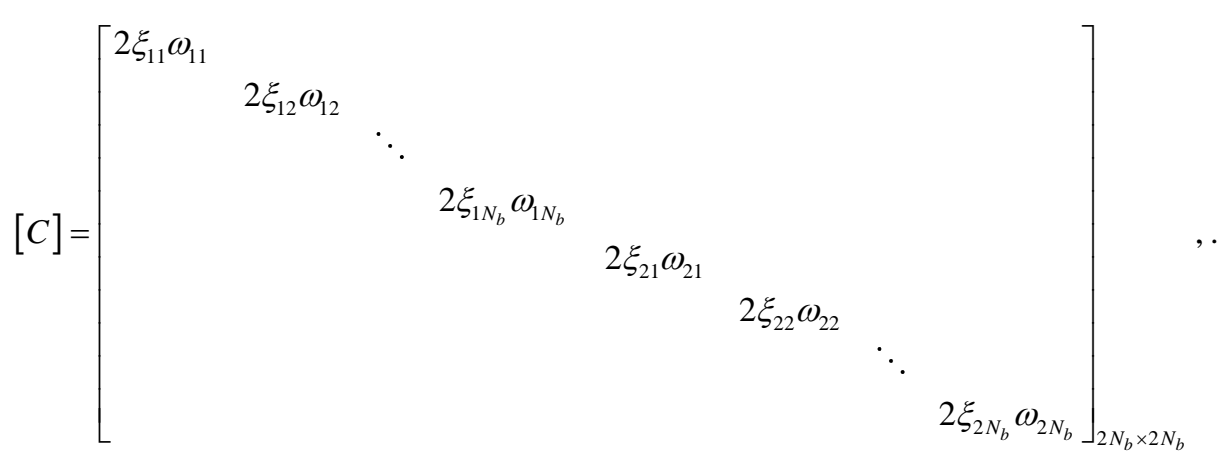

$[K]=$

$$
=\left[\begin{array}{cccccccc}
\omega_{11}^{2}+K_{m 1} \Phi_{1111} & K_{m 1} \Phi_{1211} & \cdots & K_{m 1} \Phi_{1 N_{b} 11} & -K_{m 1} \Phi_{2111} & -K_{m 1} \Phi_{2211} & \cdots & -K_{m 1} \Phi_{2 N_{b} 11} \\
K_{m 1} \Phi_{1112} & \omega_{12}^{2}+K_{m 1} \Phi_{1212} & \cdots & K_{m 1} \Phi_{1 N_{b} 12} & -K_{m 1} \Phi_{2112} & -K_{m 1} \Phi_{2212} & \cdots & -K_{m 1} \Phi_{2 N_{b} 12} \\
\ldots & \ldots & \ddots & \ldots & \ldots & \cdots & \ddots & \cdots \\
K_{m 1} \Phi_{111 N_{b}} & K_{m 1} \Phi_{121 N_{b}} & \cdots & \omega_{1 N_{b}}^{2}+K_{m 1} \Phi_{1 N_{b} 1 N_{b}} & -K_{m 1} \Phi_{211 N_{b}} & -K_{m 1} \Phi_{221 N_{b}} & \cdots & -K_{m 1} \Phi_{2 N_{b} 1 N_{b}} \\
-K_{m 2} \Phi_{1121} & -K_{m 2} \Phi_{1221} & \cdots & -K_{m 2} \Phi_{1 N_{b} 21} & \omega_{21}^{2}+K_{m 2} \Phi_{2121} & K_{m 2} \Phi_{2221} & \cdots & K_{m 2} \Phi_{2 N_{b} 21} \\
-K_{m 2} \Phi_{1122} & -K_{m 2} \Phi_{1222} & \cdots & -K_{m 2} \Phi_{1 N_{b} 22} & K_{m 2} \Phi_{2122} & \omega_{22}^{2}+K_{m 2} \Phi_{2222} & \cdots & K_{m 2} \Phi_{2 N_{b} 22} \\
\cdots & \ldots & \ddots & \ldots & \ldots & \cdots & \ddots & \cdots \\
-K_{m 2} \Phi_{112 N_{b}} & -K_{m 2} \Phi_{122 N_{b}} & \cdots & -K_{m 2} \Phi_{1 N_{b} 2 N_{b}} & K_{m 2} \Phi_{212 N_{b}} & K_{m 2} \Phi_{222 N_{b}} & \cdots & \omega_{2 N_{b}}^{2}+K_{m 2} \Phi_{2 N_{b} 2 N_{b}}
\end{array}\right]_{2 N_{b} \times 2 N_{b}}
$$

where: $K_{m 1} \Phi_{1 i 1 n}=\frac{k}{M_{1 n}} \sum_{j=1}^{d-1} \phi_{1 i}\left(x_{j}\right) \phi_{1 n}\left(x_{j}\right)+\frac{k_{r}}{M_{1 n}} \sum_{j=d} \phi_{1 i}\left(x_{j}\right) \phi_{1 n}\left(x_{j}\right)+\frac{k}{M_{1 n}} \sum_{j=d+1}^{N} \phi_{1 i}\left(x_{j}\right) \phi_{1 n}\left(x_{j}\right)$;

$K_{m 1} \Phi_{2 i 1 n}=\frac{k}{M_{1 n}} \sum_{j=1}^{d-1} \phi_{2 i}\left(x_{j}\right) \phi_{1 n}\left(x_{j}\right)+\frac{k_{r}}{M_{1 n}} \sum_{j=d} \phi_{2 i}\left(x_{j}\right) \phi_{1 n}\left(x_{j}\right)+\frac{k}{M_{1 n}} \sum_{j=d+1}^{N} \phi_{2 i}\left(x_{j}\right) \phi_{1 n}\left(x_{j}\right) ;$

$K_{m 2} \Phi_{2 i 2 n}=\frac{k}{M_{2 n}} \sum_{j=1}^{d-1} \phi_{2 i}\left(x_{j}\right) \phi_{2 n}\left(x_{j}\right)+\frac{k_{r}}{M_{2 n}} \sum_{j=d} \phi_{2 i}\left(x_{j}\right) \phi_{2 n}\left(x_{j}\right)+\frac{k}{M_{2 n}} \sum_{j=d+1}^{N} \phi_{2 i}\left(x_{j}\right) \phi_{2 n}\left(x_{j}\right) ;$

$K_{m 2} \Phi_{1 i 2 n}=\frac{k}{M_{2 n}} \sum_{j=1}^{d-1} \phi_{1 i}\left(x_{j}\right) \phi_{2 n}\left(x_{j}\right)+\frac{k_{r}}{M_{2 n}} \sum_{j=d} \phi_{1 i}\left(x_{j}\right) \phi_{2 n}\left(x_{j}\right)+\frac{k}{M_{2 n}} \sum_{j=d+1}^{N} \phi_{1 i}\left(x_{j}\right) \phi_{2 n}\left(x_{j}\right)$.

As shown in Eq. (15), the dynamic responses of the double beam system can be calculated using a step-by-step integration method. When the moving sinusoidal load travels over the double beam system, the mass, damping and stiffness matrices $[M],[C],[K]$ in Eq. (15) vary with time. Therefore, during each time step the matrices $[M],[C],[K]$ and the vector of external forces need to be updated. In this paper, the integration procedure of Newmark $\beta$ method with constant acceleration of $\beta=1 / 4$ and $\gamma=1 / 2$ are selected, which consists of the following equations [18-20].

$$
\begin{aligned}
& \{\ddot{U}\}_{t+\Delta t}=\frac{1}{\beta \Delta t^{2}}\left(\{U\}_{t+\Delta t}-\{U\}_{t}\right)- \\
& -\frac{1}{\beta \Delta t}\{\dot{U}\}_{t}-\left(\frac{1}{2 \beta}-1\right)\{\ddot{U}\}_{t}, \\
& \{\dot{U}\}_{t+\Delta t}=\{\dot{U}\}_{t}+\Delta t\left[(1-\gamma)\{\ddot{U}\}_{t}+\gamma\{\ddot{U}\}_{t+\Delta t}\right]
\end{aligned}
$$

\section{Feasibility of connection damage detection}

As shown in Fig. 1, the moving sinusoidal load travels over the double beam system at a constant speed $v$, and the properties of the double beam system and moving sinusoidal load are listed in Table 1.
In this paper, a sufficient number of modes in Eqs. (7) and (8) should be determined to calculate the dynamic responses of the upper and lower beams via the mode superposition method. For the simple supported beam, it is usually that 20 modes are enough for accuracy of the response from Eq. (15), which are also used herein [21, 22]. In the following numerical example, a time step of $0.001 \mathrm{~s}$ and ending time of $t_{\text {end }}=L / v$ are employed to compute the dynamic responses of the double beam under moving load.

Table 1

Properties of the double beam system and moving sinusoidal load

\begin{tabular}{|c|c|c|c|c|c|c|}
\hline$m_{1}, \mathrm{~kg} / \mathrm{m}$ & $E_{1}, \mathrm{~N} / \mathrm{m}^{2}$ & $I_{1}, \mathrm{~m}^{4}$ & $\xi_{1}$ & $L, \mathrm{~m}$ & $L, \mathrm{~m}$ & $K, \mathrm{~N} / \mathrm{m}$ \\
\hline 3250 & $2.15 \times 10^{10}$ & 0.65 & $2 \%$ & 36 & 6 & $3.2 \times 10^{7}$ \\
\hline$m_{2}, \mathrm{~kg} / \mathrm{m}$ & $E_{2}, \mathrm{~N} / \mathrm{m}^{2}$ & $I_{2}, \mathrm{~m}^{4}$ & $\xi_{2}$ & $N$ & $P_{0}, \mathrm{kN}$ & $\omega_{0}, \mathrm{~Hz}$ \\
\hline 6250 & $3.05 \times 10^{10}$ & 2.65 & $5 \%$ & 5 & 800 & 2.268 \\
\hline
\end{tabular}

To study the connection damage of the spring on the dynamic responses of the double beam system, let us consider the 3rd spring damaged with the stiffness reduction of $50 \%$ as the initial value, that is $k_{r}=(1-50 \%) k=0.5 k$. When the speed of the moving load is $10 \mathrm{~m} / \mathrm{s}$, the accelerations of the upper beam at midspan before and after danmage are compared, as shown in Fig. 2. The maximum accelerations 
$A_{\max }$ of the upper beam at different locations, such as $L / 8$, $L / 4,3 L / 8, L / 2,5 L / 8,3 L / 4$, and $7 L / 8$ are list in Table 2 .

It indicates that from Fig. 2, when the moving load travels over the damaged doubele beam system with the stiffness reduction of the spring support, the acceleration of the upper beam is with a slight increase. The changing of the dynamic responses of the double beam system before and after damage also can be confirmed in Table 2. This shows the possibility of the proposed damage detection approach using the structural dynamic responses with genetic algorithm, which will be introduced below.

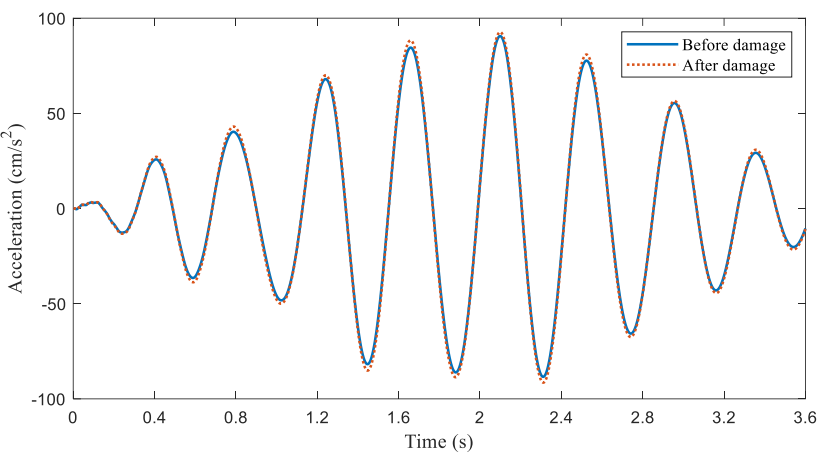

Fig. 2 Accelerations of the upper beam system at mid span

Table 2

Maximum accelerations $A_{\max }$ of the upper beam

\begin{tabular}{|c|c|c|c|c|c|c|c|}
\hline$A_{\max }, \mathrm{cm} / \mathrm{s}^{2}$ & $L / 8$ & $L / 4$ & $3 L / 8$ & $L / 2$ & $5 L / 8$ & $3 L / 4$ & $7 L / 8$ \\
\hline Before damage & 20.63 & 45.46 & 72.09 & 90.60 & 92.26 & 73.98 & 40.90 \\
\hline After damage & 22.08 & 48.14 & 74.10 & 92.72 & 94.21 & 75.48 & 41.71 \\
\hline
\end{tabular}

\section{Damage detection process with genetic algorithm}

Genetic algorithm was motivated by biological genetic and evolution mechanisms and had been applied successfully in engineering optimization problems [23, 24]. The method is powerful at global convergence, high precision, and less computation time under the same precision requirements than other optimization methods. Therefrore, genetic algorithm is widely used in multiobjective optimization problem, combinatorial optimization, pattern recognition and so on. To find the global optimum from a complex surface, the solutions from genetic algorithm is created using selection, crossover and mutation operators such as the natural selection.

In this paper, the genetic algorithm is used to detecte the spring connection damage of the double beam system. The damage degree of spring connections are treated as discrete values, and each value is encoded by a binary digits gene string with gray code. In this paper, each discrete value is encoded by a three binary digits gene string, which can be used to detect 0 to 70 percent stiffness reduction of spring connection, as given in Table 3. From pratical view, for higher spring stiffness reduction such as $80 \%, 90 \%, 100 \%$ can be found through visual inspection, and these damaged cases are not studied through numerical investigations in the following. Then, an individual (chromosome) consisting of 5 gene strings is used to represent the stiffness $k$ of 5 springs in double beam system in Fig. 1 , which is used as the input data for the spring connection prarmeters between the upper and lower beams.

Table 3

Binary digits gene string with gray code

\begin{tabular}{|c|c|c|c|c|c|c|c|c|}
\hline Gene string & 000 & 001 & 011 & 010 & 110 & 111 & 101 & 100 \\
\hline Damage degree, $\%$ & 0 & 10 & 20 & 30 & 40 & 50 & 60 & 70 \\
\hline
\end{tabular}

The procedure of spring connection damage detection of doubel beam system using beam vibration and genetic algorithm is shown in Fig. 3.

For the procedure of damage detection with genetic algorithm in Fig. 3, it is can be divided into two main groups. The first one is to compute the dynamic responses of double beam under moving load with certain damage state, including

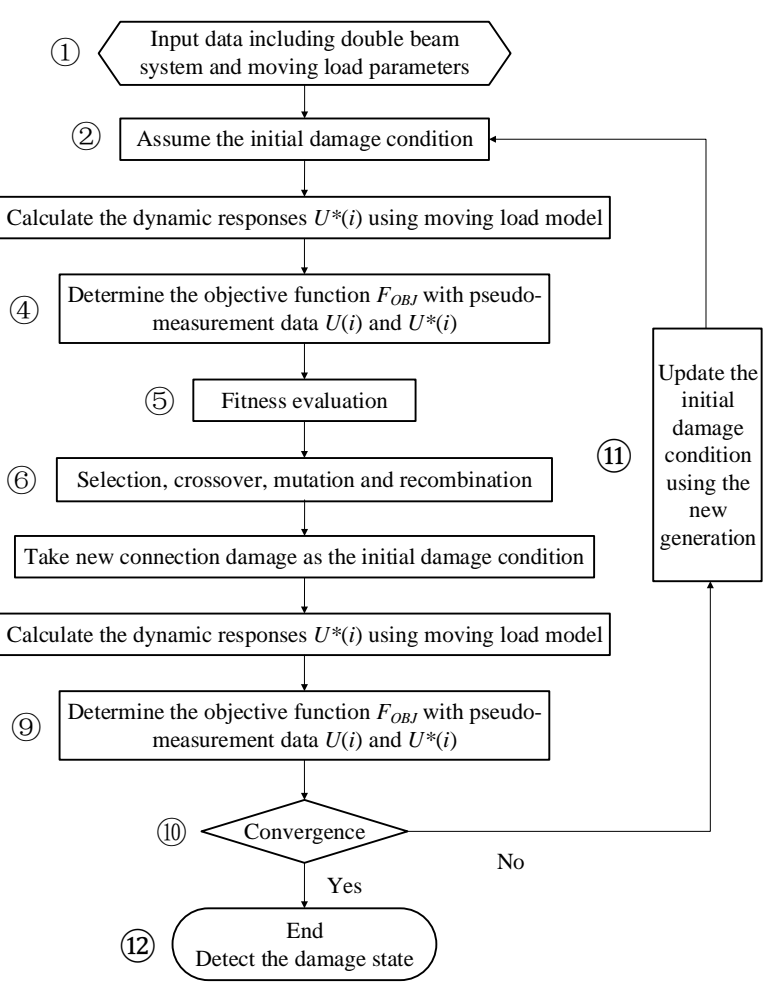

Fig. 3 Procedure of damage detection with genetic algorithm

steps (3), (8). And the second one is to perform the spring damage detection with genetic algorithm method, including steps (4), (5), 6), (7), (9), (11). In this paper, the damage detection procedure, including the two main groups and other steps (1), (2), (10), (12) in Fig. 3 are executed by MATLAB codes. During the detection process, the dynamic responses of the double beam system with some certain known preassumed damage state are calculated using the developed moving load model in Section 2 first, which are set as the pseudo-measurement data $U(i)$. In this paper, the objective function $F_{o b j}$ in Fig. 3 is defined as the difference between the computed acceleration response and the pseudomeasurement data: 


$$
F_{o b j}=\frac{1}{N} \sum\left\{U(i)-U^{*}(i)\right\}
$$

where: $U(i)$ is the vector of the discrete values of pseudomeasurement data with certain pre-assumed damage state and $U^{*}(i)$ is the vector of the computed results calculated by the dynamic moving load model developed in Section 2 with some damage state generated by the genetic algorithm process. During the pratical mearuments some noise may be included in the measurement data, which will make some differences between the pseudo-measurement data and the computed results. However, this is the first attempt to using the structural dynamic responses with genetic algorithm to detect connection damages of double beam system. All the research herein are focused on the theoretical study, and the measurement noise is not considered bellow.

The objective function $F_{o b j}$ in Eq. (23) is used as fitness function value in the detection process. The effectiveness of the genetic algorithm depends greatly on the crossover and mutation rate values, which are set as 60 and 10 percent, respectively, in this study [25]. During detection process, the minimum value of $F_{o b j}$ is determined, the detection process determines that the identified damage state is in agreement with the pre-assumed damage state.

\section{Numerical investigation}

Due to the springs manufacturing and installing, there may be some initial faults for the connection between the upper and lower beams. Also, the spring connection of the double beam system may degerate during services, especially under the impact of moving loads. To investigate the connection detection feasibility of the proposed approach in Section 4, the simple damage and multiple damages dection will be considered herien. The connection damage is expressed by a uniform decrease of the spring stiffness. For example, if the $i$ th spring connection has 20 percent damage, and it means that the stiffness of the $i$ th spring loses 20 percent and the value is the 80 percent of the initial value. During the damage detection process, the acceleration response of the upper beam at midpoint is used as the input data for objective function in Eq. (23). During connection damage detection calculation, the computed time of one generation is almost the same, so the calculated generations $C G$ can be set as an index to represent the identification efficiency. In the following numerical studies, it is assumed that the moving load travels at a low speed of $10 \mathrm{~m} / \mathrm{s}$ for all the cases.

\subsection{Simple damage detection}

For simple damage detection, it is assumed that one spring connection of the double beam system is damaged. The location and degree of the damaged spring should be detected simultaneously, which are the targets of the identification. In this paper, the following three simple damage cases are considered. Case 1 indicates the $1^{\text {st }}$ spring connection is damaged and the damage is light with 10 percent stiffness reduction. For Case 2, there is a light damage state for $3^{\text {rd }}$ spring connection. And Case 3 represents a severe damage state for the $3^{\text {rd }}$ spring connection, and the stiffness loses 70 percent. The identification results and calculated generations $C G$ for simple damage detection are list in Table 4.

Case 1: the $1^{\text {st }}$ spring connection has 10 percent damage; Case 2: the $3^{\text {rd }}$ spring connection has 10 percent damage; Case 3: the $3^{\text {rd }}$ spring connection has 70 percent damage.

Table 4

Results for simple damage detection

\begin{tabular}{|c|c|c|c|c|c|c|}
\hline \multirow{2}{*}{$\begin{array}{c}\text { Spring } \\
\text { No. }\end{array}$} & \multicolumn{2}{|c|}{ Case 1 } & \multicolumn{2}{c|}{ Case 2 } & \multicolumn{2}{c|}{ Case 3 } \\
\cline { 2 - 7 } & $\begin{array}{c}\text { Pseudo- } \\
\text { measured }\end{array}$ & $\begin{array}{c}\text { Com- } \\
\text { puted }\end{array}$ & $\begin{array}{c}\text { Pseudo- } \\
\text { measured }\end{array}$ & $\begin{array}{c}\text { Com- } \\
\text { puted }\end{array}$ & $\begin{array}{c}\text { Pseudo- } \\
\text { measured }\end{array}$ & $\begin{array}{c}\text { Com- } \\
\text { puted }\end{array}$ \\
\hline 1 & 10 & 10 & 0 & 0 & 0 & 0 \\
\hline 2 & 0 & 0 & 0 & 0 & 0 & 0 \\
\hline 3 & 0 & 0 & 10 & 10 & 70 & 70 \\
\hline 4 & 0 & 0 & 0 & 0 & 0 & 0 \\
\hline 5 & 0 & 0 & 0 & 0 & 0 & 0 \\
\hline$C G$ & \multicolumn{2}{|c|}{20} & \multicolumn{2}{|c|}{25} & \multicolumn{2}{c|}{126} \\
\hline
\end{tabular}

From the identification results in Table 4, the values of damage degrees for all spring connections in Case 1, 2, and 3 are consistent with the pre-assumed damage state. It indicates that the damage pattern, including damage location and degree, can be identified by the proposed detection approach using the upper beam acceleration and genetic algorithm in Section 4. Table 4 indicates the calculated generations $C G$ are 20, 25, and 126 for Case 1, 2, and 3, respectively. It shows that the bigger damage degree case needs much longer time to detect sucessfully.

Here we take the Case 2 to study the objective function $F_{o b j}$ variations during the detection process, the objective function of Case 2 against calculated generation is show in Fig. 4. For the $15^{\text {th }}$ and $17^{\text {th }}$ iteration, the local minimum of objective function $F_{o b j}$ is determined, see the regional enlarged drawing in Fig. 4. It indicates that the jumping ability of objective function $F_{o b j}$ is implemented due to the genetic and evolution mechanism of genetic algorithm. At last the minimum value of objective function $F_{o b j}$ can be reached, in this numerical investigation the vaule is 0 , and the real damage state is found by genetic algorithm method also.

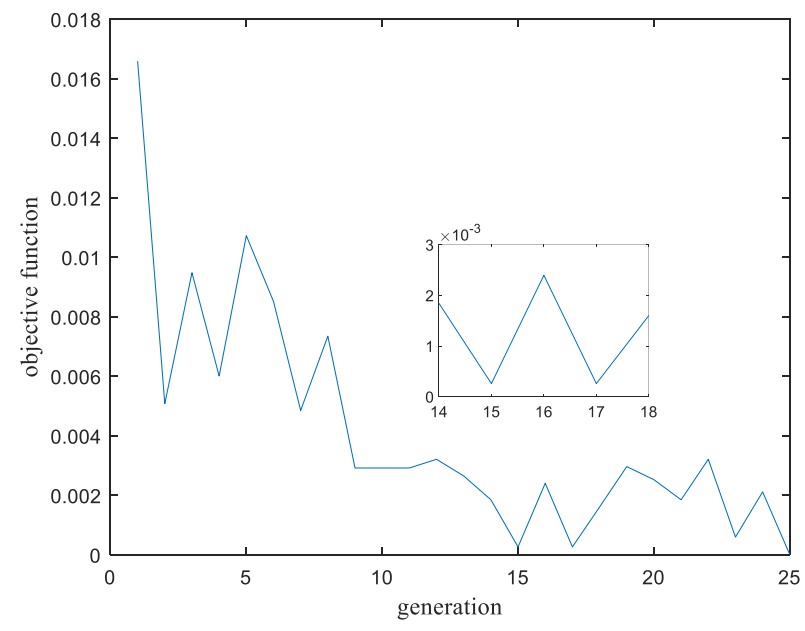

Fig. 4 Objective function of Case 2

\subsection{Multiple damages detection}

To investigate the feasibility of multiple connection damages detection, two or three spring connection damages are assumed in the folowing cases. The identification results and calculated generations $C G$ for multiple damages detection are calculated in Table 5. 
Case 4: the $1^{\text {st }}$ spring connection has 10 percent damage and the $2^{\text {nd }}$ has 20 percent damage;

Case 5: the $2^{\text {nd }}$ spring connection has 10 percent damage and the $3^{\text {rd }}$ has 20 percent damage;

Case 6: the $2^{\text {nd }}, 3^{\text {rd }}$, and $4^{\text {th }}$ spring connections have 20,50 , and 20 percent damages, respectivelly.

Table 5

Results for multiple damages detection

\begin{tabular}{|c|c|c|c|c|c|c|}
\hline \multirow{2}{*}{$\begin{array}{c}\text { Spring } \\
\text { No. }\end{array}$} & \multicolumn{2}{|c|}{ Case 4 } & \multicolumn{2}{c|}{ Case 5 } & \multicolumn{2}{c|}{ Case 6 } \\
\cline { 2 - 7 } & $\begin{array}{c}\text { Pseudo- } \\
\text { measured }\end{array}$ & $\begin{array}{c}\text { Com- } \\
\text { puted }\end{array}$ & $\begin{array}{c}\text { Pseudo- } \\
\text { measured }\end{array}$ & $\begin{array}{c}\text { Comp- } \\
\text { uted }\end{array}$ & $\begin{array}{c}\text { Pseudo- } \\
\text { measured }\end{array}$ & $\begin{array}{c}\text { Com- } \\
\text { puted }\end{array}$ \\
\hline 1 & 10 & 10 & 0 & 0 & 0 & 0 \\
\hline 2 & 20 & 20 & 10 & 10 & 20 & 20 \\
\hline 3 & 0 & 0 & 20 & 20 & 50 & 50 \\
\hline 4 & 0 & 0 & 0 & 0 & 20 & 20 \\
\hline 5 & 0 & 0 & 0 & 0 & 0 & 0 \\
\hline$C G$ & \multicolumn{3}{|c|}{50} & \multicolumn{2}{|c|}{131} & \multicolumn{2}{c|}{324} \\
\hline
\end{tabular}

The identification results in Table 5 show that the identified damage location and degrees are the same as the pre-assumed damage state. The possibility of the proposed detection approach combined the upper beam acceleration with genetic algorithm in Section 4 is verified. The calculated generations for Case 4, 5, and 6 are 50, 131, and 324, respectively, and the tendency is that the case with multiple damages detection needs longer calculation time.

For multiple damages detection, the objective function of Case 4 against calculated generation is show in Fig. 5. It shows that the value of objective function $F_{o b j}$ jumps to the minimum value 0 after 50 generation iteration last, and the the real damage state is found sucessfully. The local minimums of objective function $F_{o b j}$ at the $18^{\text {th }}$ and $44^{\text {th }}$ iteration is also shown in Fig. 5.

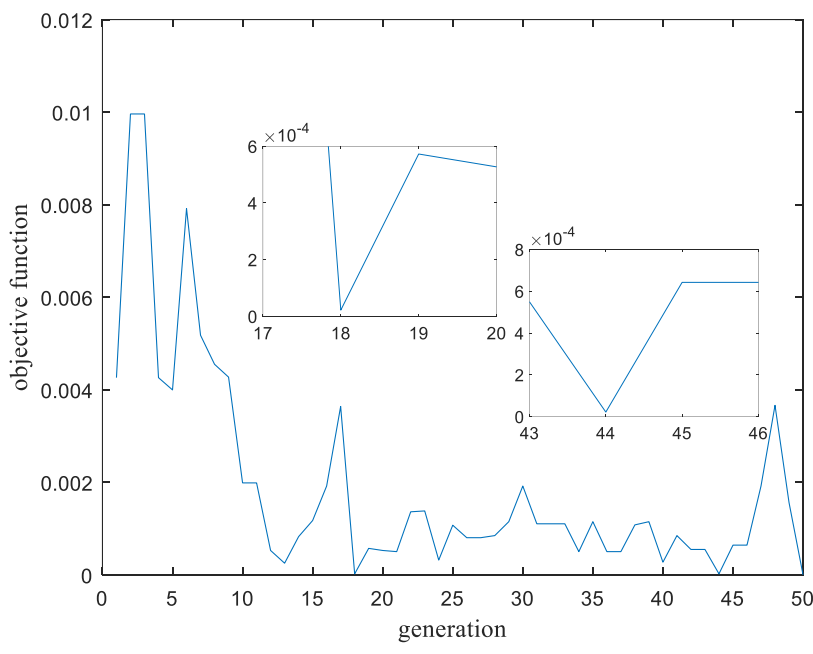

Fig. 5 Objective function of Case 4

\section{Conclusions}

In this paper, a connection damage detection approach for double beam system combined the structural dynamic responses with genetic algorithm is proposed and verified through numerical studies. The dynamic model of the double beam system subjected to moving load is presented and the responses of both beam are calculated by the Newmark- $\beta$ method. The process of the proposed connection damage detection approach is proposed herien, and its feasibility is numerically investigated through simple damage and multiple damages cases. No matter the damage location and damage degree can be identified sucessfully. For the sophisticated damage conditions, it indicates that the calculated generation is much bigger, and it means the detection process needs much longer time. In the future studies, the feasibility of the proposed detection approach will be adopted for a double beam model in laboratory to verify the damage detection results.

\section{Acknowledgments}

The authors wish to express their thanks to Beijing Natural Science Foundation (No. 3184047), Beijing Academy of Science and Technology Funds (No. PY2020AQ03) \& (No.OTP-2018-002) and National Natural Science Foundation of China (No. 51408036).

\section{References}

1. Stojanović, V.; Kozić, P. 2015. Vibrations and Stability of Complex Beam Systems. Switzerland: Springer. $165 \mathrm{p}$.

http://dx.doi.org 10.1007/978-3-319-13767-4.

2. Lei, X. 2017. High Speed Railway Track Dynamics. Singapore: Springer. 414 p. http://dx.doi.org/10.1007/978-981-10-2039-1.

3. Mohammadzadeh, S.; Esmaeili, M.; Mehrali, M. 2014. Dynamic response of double beam rested on stochastic foundation under harmonic moving load, International Journal for Numerical and Analytical Methods in Geomechanics 38(6), 572-592.

http://dx.doi.org/10.1002/nag.2227.

4. Liang, L.; Li, X.; Yin, J.; Wang, D.; Gao, W.; Guo, Z. 2019. Vibration characteristics of damping pad floating slab on the long-span steel truss cable-stayed bridge in urban rail transit, Engineering Structures 191: 92-103.

http://dx.doi.org/10.1016/j.engstruct.2019.04.032.

5. Zhang, L.; Ou, Q.; Zhao, M. 2018. Double-beam model to analyze the performance of a pavement structure on geocell-reinforced embankment, Journal of Engineering Mechanics 144(060180028). http://dx.doi.org/10.1061/(ASCE)EM.19437889.0001453.

6. Abu-Hilal, M. 2006. Dynamic response of a double Euler-Bernoulli beam due to a moving constant load, Journal of Sound and Vibration 297(3-5): 477-491. http://dx.doi.org/10.1016/j.jsv.2006.03.050.

7. Zhang, Y. Q.; Lu, Y.; Ma, G. W. 2008. Effect of compressive axial load on forced transverse vibrations of a double-beam system, International Journal of Mechanical Sciences 50(2): 299-305. http://dx.doi.org/10.1016/j.ijmecsci.2007.06.003.

8. Balkaya, M.; Kaya, M. O.; Saglamer, A. 2010. Free transverse vibrations of an elastically connected simply supported twin pipe system, Structural Engineering and Mechanics 34(5): 549-561

http://dx.doi.org/10.12989/sem.2010.34.5.549.

9. Huang, M.; Liu, J. K. 2013. Substructural method for vibration analysis of the elastically connected doublebeam system, Advances in Structural Engineering 16(2): 365-377.

http://dx.doi.org/10.1260/1369-4332.16.2.365. 
10. Koziol, P. 2014. Wavelet approximation of adomian's decomposition applied to the nonlinear problem of a double-beam response subject to a series of moving loads, Journal of Theoretical and Applied Mechanics 52(3): 687-697.

11. Jiang, L.; Zhang, Y.; Feng, Y.; Zhou, W.; Tan, Z. 2019. Dynamic response analysis of a simply supported double-beam system under successive moving loads, Applied Sciences 9: 2162. http://dx.doi.org/10.3390/app9102162.

12. Li, J.; Zhang, H. 2020. Moving load spectrum for analyzing the extreme response of bridge free vibration, Shock and Vibration 9431620. http://dx.doi.org/10.1155/2020/9431620.

13. Yau, J.; Fryba, L. 2015. A quasi-vehicle/bridge interaction model for high speed railways, Journal of Mechanics 31(2): 217-225. http://dx.doi.org/10.1017/jmech.2014.89.

14. Luu, M.; Martinez-Rodrigo, M. D.; Zabel, V.; Könke, C. 2014. Semi-active magnetorheological dampers for reducing response of high-speed railway bridges, Control Engineering Practice 32: 147-160. http://dx.doi.org/10.1016/j.conengprac.2014.08.006.

15. Yang, Y. B.; Yau, J. D.; Urushadze, S. 2019. Wave transmission of linked railcars moving over multi simple beams under dual resonance, Journal of Sound and Vibration 452: 51-57. http://dx.doi.org/10.1016/j.jsv.2019.03.020.

16. Yang, Y. B.; Yau, J. D. 2017. Resonance of highspeed trains moving over a series of simple or continuous beams with non-ballasted tracks, Engineering Structures 143: 295-305. http://dx.doi.org/10.1016/j.engstruct.2017.04.022.

17. Yau, J. D.; Martinez-Rodrigo, M. D.; Domenech, A. 2019. An equivalent additional damping approach to assess vehicle-bridge interaction for train-induced vibration of short-span railway bridges, Engineering Structures 188: 469-479.

http://dx.doi.org/10.1016/j.engstruct.2019.01.144.

18. Zhu, X. Q.; Law, S. S. 2015. Structural health monitoring based on vehicle-bridge interaction: accomplishments and challenges, Advances in Structural Engineering 18(12): 1999-2015. http://dx.doi.org/10.1260/1369-4332.18.12.1999.

19. Xin, L.; Li, X.; Zhu, Y.; Liu, M. 2019. Uncertainty and sensitivity analysis for train-ballasted track-bridge system, Vehicle System Dynamics: 1-19. http://dx.doi.org/10.1080/00423114.2019.1584678.

20.Zhu, Z.; Gong, W.; Wang, L.; Bai, Y.; Yu, Z.; Zhang, L. 2019. Efficient assessment of 3D traintrack-bridge interaction combining multi-time-step method and moving track technique, Engineering Structures 183: 290-302. http://dx.doi.org/10.1016/j.engstruct.2019.01.036.

21. Yau, J. D. 2012. Lateral vibration control of a lowspeed maglev vehicle in cross winds, Wind and Structures 15(3): 263-283. http://dx.doi.org/10.12989/was.2012.15.3.263.

22. Wang, Y. J.; Shi, J.; Xia, Y. 2012. Dynamic responses of an elastic beam moving over a simple beam using modal superposition method, Journal of Vibroengineering 14(4): 1824-1832.

23. Rodrigues, A. F. S.; Dimitrovova, Z. 2015. Optimization of the behaviour of high-speed railway tracks using a genetic algorithm approach, Proceedings of the Institution of Mechanical Engineers Part F-Journal of Rail and Rapid Transit 229(4): 345-363. http://dx.doi.org/10.1177/0954409714537252.

24. Haupt, R. L.; Haupt, S. E. 2004. Practical Genetic Algorithms (2nd Edition). New Jersey, US: John Wiely \& Sons, Inc. 253p. http://dx.doi.org/10.1002/0471671746.

25. Koh, H. G.; Perry, M. J. 2010. Structural Identification and Damage Detection using Genetic Algorithms. London, UK: CRC Press. 140 p.

H. Zhang, R. Song, J. Yang, D. Wu, Y. Wang

\section{CONNECTION DAMAGE DETECTION OF DOUBLE BEAM SYSTEM UNDER MOVING LOAD WITH GENETIC ALGORITHM}

S u m m a r y

In this paper, a novel damage detection approach for the spring connection of the double beam system using the dynamic response of the beam and genetic algorithm is presented. The double beam system is regarded as both Bernoulli-Euler beams with simply supported ends, the upper and lower beams are connected by a series of linear springs with certain intervals. With the genetic algorithm, the dynamic acceleration response of double beam system under moving load, which can be solved by the Newmark$\beta$ integration procedure, is used as the input data to detect the connection damage. Thus the dynamic response of the double beam system with a certain damage pattern can be calculated employing the moving load model. If the calculated result is quite close to the recorded response of the damaged bridge, this damage pattern will be the solution. The connection damage detection process of the proposed approach is presented herein, and its feasibility is studied from the numerical investigation with simple and multiple damages detection. It is concluded that the sophisticated damage conditions need much longer time to detect successfully.

Keywords: double beam system, connection damage detection, moving load, genetic algorithm.

Received March 15, 2020 Accepted February 17, 2021 